\title{
Management of tennis elbow
}

This article was published in the following Dove Press journal:

Open Access Journal of Sports Medicine

9 June 2011

Number of times this article has been viewed

\section{Linda S Chesterton \\ Christian D Mallen \\ Elaine M Hay}

Arthritis Research UK Primary Care Centre, Primary Care Sciences, Keele University, Keele, Staffordshire, UK

Date of preparation:April 2I, 20II Conflict of interest: None declared
Correspondence: Christian D Mallen Professor of General Practice, Arthritis Research UK Primary Care Centre, Primary Care Sciences, Keele University, Keele, Staffordshire, ST5 5BG, UK Tel +44 (0) I 782734879

$\mathrm{Fax}+44(0)$ । 782 7339| ।

Email c.d.mallen@cphc.keele.ac.uk
Clinical question: What is the best treatment for tennis elbow?

Results: Despite a wealth of research, there is no true consensus on the most efficacious management of tennis elbow especially for effective long-term outcomes. Corticosteroid injections do show large pain-relieving effects in the short term but are associated with risks of adverse events and long-term reoccurrence. Advice with a "wait and see" approach is recommended as the first-line treatment in primary care for most cases. In the medium term physiotherapy and or low-level laser therapy may be effective.

Implementation: Rule out alternative diagnosis. Onward referral may be indicated if the condition does not resolve after 12 months.

Keywords: tennis elbow, corticosteroids, physiotherapy, laser therapy

\section{Tennis elbow}

Definition: Tennis elbow, also known as lateral epicondylalgia (LE) and often referred to as epicondylitis or tendinopathy clinically, ${ }^{1}$ has a complex underlying pathophysiology which is not well understood but is characterized by uncomplicated signs of localized pain over the lateral epicondyle which is made worse with resisted wrist extension and grip. ${ }^{2}$ The term epicondylitis has recently been considered a misnomer because a lack of inflammatory signs.

Etiology: The annual incidence of tennis elbow is 4 to 7 cases per 1000 patients, predominantly in patients aged 35 to 55 years. ${ }^{3,4}$ The condition affects between $1 \%$ and $3 \%$ of the population, ${ }^{5,6}$ is usually self-limiting, and lasts between 6 and 24 months. ${ }^{4}$ Twenty percent of cases persist for more than a year. ${ }^{7}$

Risk factors: Repetitive manual tasks, or handling of heavy loads ( $>20 \mathrm{~kg}$ ) or heavy tools $(>1 \mathrm{~kg}) .{ }^{8}$ Risk is increased by a working posture of arms raised in front of the body, coupled with repetitive forearm twisting or rotating motions. The risk is further increased by high gripping force. ${ }^{9} \mathrm{LE}$ is also associated with computer use of more than 20 hours per week, a risk that increases in line with years of use. ${ }^{10}$

Economics: Up to $30 \%$ of patients report work absenteeism.

Level of evidence: Systematic reviews, meta-analyses, general reviews, and randomized controlled trials (RCTs).

Search sources: MEDLINE (PubMed), CINHAL, EMBASE, AMED, Web of Knowledge, SPORTDiscus, Cochrane Library, DARE, DHdata, PEDro. 
Outcomes: From a patient perspective the main outcomes are:

- Pain relief at rest and on activity.

- Improved function.

- Reduced sick leave.

- Avoidance of adverse events.

These are frequently measured in the short ( 0 to 12 weeks), intermediate (13 to 26 weeks), and long term ( $\geq 52$ weeks).

Consumer summary: Tennis elbow is a common, painful condition that generally occurs in middle-aged people and often prevents them from working or participating in their usual daily activities. Despite a large number of studies investigating an array of interventions, there is no favored evidence-based treatment for tennis elbow that gives anything beyond short-term pain relief. Corticosteroid injections do show large benefits in the short term, but can be painful and are associated with an increased risk of long-term recurrence, especially if more than one injection is given. There is some evidence that low-level laser therapy (LLLT) may be beneficial in the short term, although this is controversial and not always available as a tretament. Combined physiotherapy treatments give some medium-term relief slightly superior to advice and analgesics alone and show significantly better outcomes than steroid injections in the long term. For those patients who do not recover or respond to treatment in the long term, there is limited low-level support for injecting blood plasma, or for persistent and severe cases to undergo surgery. Advice with prescribed over-the-counter pain medication is recommended as the first-line treatment for most cases.

\section{The evidence}

Systematic reviews

17

Meta-analysis

General reviews

RCTs

\section{Are injection therapies beneficial?}

\section{(a) Corticosteroid agents}

Steroid injections are the most thoroughly investigated intervention. There are 4 systematic reviews, ${ }^{12-15}$ the most recent reporting 18 separate analyses from 12 trials $(n=1171$ patients). ${ }^{14}$ Coombes et al ${ }^{14}$ concluded that there was strong evidence for the short-term benefit of corticosteroid injections across all outcome measures. Despite heterogeneity within the included trials which prevented pooling of some data for meta-analysis, consistent large effect sizes were seen in favor of corticosteroid injections compared with no intervention ("wait and see"), non-steroidal anti-inflammatory drugs (NSAIDs), physiotherapy, orthotic devices, and platelet-rich plasma (PRP) injections (reported in a separate review). ${ }^{16}$ These findings are in agreement with previous meta-analyses of the same subject ${ }^{12,13}$ and with a recent systematic review restricted to comparing corticosteroid injections with various (individual as opposed to combined) physiotherapy interventions. ${ }^{15}$ One exception to this was the comparison with NSAIDS, in which Gaujoux-Viala et $\mathrm{al}^{13}$ reported that corticosteroids were not better in the short term $(n=1113)$.

In the intermediate and longer term, Coombes et $\mathrm{al}^{14}$ reported strong evidence that corticosteroid injections are less beneficial and show more adverse responses than all other interventions. This is also in agreement with a previous analysis. ${ }^{7}$ The authors report a subanalysis, which included the variable quality of trials, and this did not alter their conclusions. Different doses and suspensions of corticosteroid did not alter outcomes, although repeated injections (average 4.3, range 3 to 6 over 18 months) were associated with poorer outcomes. ${ }^{14}$ Gaujoux-Viala et $\mathrm{al}^{13}$ also reported a sensitivity analysis for disease duration which suggested that steroid injections are more effective in acute and subacute tendonitis (duration $<12$ weeks) than in chronic disease, although the authors did suggest publication bias in favor of positive trials.

In the Coombes et al review, ${ }^{14} 82 \%$ of trials using corticosteroid injections reported adverse events which affected $17 \%$ of patients ( $n=72 / 416$; atrophy 38 , pain 31 , depigmentation 2, rupture 1). Another trial also reported high reoccurrence rates. ${ }^{17}$ A number needed to harm (NNH) of 26 for corticosteroid injections versus other commonly used treatments was reported. ${ }^{13}$ (The NNH is the number of patients who, if they received treatment, would lead to one additional person being harmed compared with patients who receive control treatments. ${ }^{18}$ )

\section{(b) Noncorticosteroid agents}

Three systematic reviews have investigated the injection of noncorticosteroid agents, although the number of relevant studies included in each is very small. ${ }^{14,19,20}$ Coombes et $\mathrm{al}^{14}$ report the following results: sodium hyaluronate provided better pain relief at all outcome points than placebo injection ( 1 study, ${ }^{21} \mathrm{n}=165$ intervention group). However 
Table I Randomized controlled trials published subsequent to the latest systematic reviews on injection therapy

\begin{tabular}{|c|c|c|c|c|}
\hline Author & $\begin{array}{l}\text { Number } \\
\text { randomized }\end{array}$ & Interventions & Outcome measures & Results \\
\hline Kazemi et $\mathrm{al}^{24}$ & 60 & $\begin{array}{l}\text { Methylprednisolone } \\
\text { or } \\
\text { Autologous blood }\end{array}$ & $\begin{array}{l}\text { Quick DASH } \\
\text { PPT } \\
\text { Modified Nirschl scores } \\
\text { At } 4 \text { and } 8 \text { weeks }\end{array}$ & $\begin{array}{l}\text { At } 4 \text { weeks autologous blood superior in: severity of } \\
\text { pain, pain in grip, PPT Quick DASH } \\
\text { No differences in Nirschl score, grip strength, and limb } \\
\text { function } \\
\text { At } 8 \text { weeks autologous blood superior for all outcomes }\end{array}$ \\
\hline Peerbooms et $\mathrm{al}^{16}$ & 100 & $\begin{array}{l}\text { PRP } \\
\text { or } \\
\text { Corticosteroid injection }\end{array}$ & $\begin{array}{l}\text { VAS } \\
\text { DASH }\end{array}$ & $\begin{array}{l}\text { Significant improvement in PRP group over steroid } \\
\text { group for pain and DASH. } \\
\text { Corticosteroid group better initially and then declined } \\
\text { PRP group progressively improved }\end{array}$ \\
\hline Ozturan et $\mathrm{al}^{25}$ & 60 & $\begin{array}{l}\text { Corticosteroid injection } \\
\text { or } \\
\text { Autologous blood } \\
\text { injection } \\
\text { or } \\
\text { ECSWT }\end{array}$ & $\begin{array}{l}\text { Thomsen provocative } \\
\text { testing } \\
\text { Upper extremity functional } \\
\text { scores, } \\
\text { maximal grip strength }\end{array}$ & $\begin{array}{l}\text { Corticosteroid injection significantly better for all } \\
\text { outcomes at } 4 \text { weeks } \\
\text { Autologous blood injection and ECSWT gave } \\
\text { significantly better Thomsen provocative test results } \\
\text { and upper extremity functional scores at } 52 \text { weeks } \\
\text { The success rate of corticosteroid injection was } 50 \% \text {, } \\
\text { which was significantly lower than the success rates } \\
\text { for autologous blood injection ( } 83.3 \%) \text { and ECSWT } \\
(89.9 \%)\end{array}$ \\
\hline
\end{tabular}

Abbreviations: ECSWT, extracorporeal shock wave therapy; PPT, pain pressure threshold; PRP, platelet-rich plasma; VAS, visual analog scale; DASH, Disabilities of the Arm, Shoulder and Hand questionnaire.

the review authors noted that the placebo group $(\mathrm{n}=166)$ in this study showed no improvement over 12 months, which is inconsistent with most other trials. No significant short-, intermediate-, or long-term effects were seen in 34 patients injected with glycosaminoglycan polysulfate (NSAID), ${ }^{22}$ or in the use of a sclerosing polidocanol versus a local anesthetic (lidocaine + epinephrine) $(\mathrm{n}=32) .{ }^{23}$

Rabago et $\mathrm{al}^{19}$ reviewed prospective case studies and controlled trials in respect of prolotherapy, polidocanol, whole blood, and PRP injections. They concluded that for LE which is refractory to conservative treatment, there is some limited pilot level evidence for the effectiveness of these therapies. For botulinum toxin a meta-analysis of 4 RCTs showed beneficial effects in the short term in pain reduction, but no effect on grip strength. ${ }^{20}$ No high quality studies have investigated long-term outcomes for any of these interventions.

No adverse effects were observed for sodium hyaluronate, lauromacrogol, prolotherapy, or PRP. Aprotinin was associated with itching and burning and botulinum toxin with weakness and paresis ${ }^{14}$ and pain at the injection site. ${ }^{20}$ Table 1 shows relevant randomized controlled trials published after the latest systematic review.

\section{Which noninjection therapies are likely to be beneficial?}

\section{Analgesia}

Fourteen RCTs included in a Cochrane review of topical and oral NSAIDs ${ }^{26}$ reported some support (small effect sizes) for the use of topical NSAIDs to relieve pain in the short term.
Two studies of oral administration of analgesics produced inconclusive evidence. Usual adverse effect profiles of oral NSAIDS need to be considered.

\section{Low-level laser therapy}

Five systematic reviews were identified. The most recent (which covered tendinopathy generally) ${ }^{27}$ utilized laser dose standards defined by the World Association for Laser Therapy (WALT) to assess adequacy of treatment within included studies. ${ }^{28}$ Twelve (from 25 ) included studies showed positive outcomes in the short term. In a previous review specific to LLLT for $L E,{ }^{29} 13$ trials ( $\mathrm{n}=730$ patients) showed reductions in pain and increased grip strength. (Comparably, corticosteroid injections show a more rapid onset in pain reduction and a larger effect size in the same period.) A subgroup analysis showed these effects were associated with narrowly defined doses of $904 \mathrm{~nm}$ wavelength LLLT (the treatment procedure is described as direct irradiation of approximately $5 \mathrm{~cm}^{2}$ of the tendon insertion at the lateral elbow, with a dose of 0.25 to 1.2 joules, and mean output 5 to $50 \mathrm{~mW}$. WALT also recommend peak pulse output $>1$ Watt, and power density of less than $100 \mathrm{~mW} / \mathrm{cm}^{2}{ }^{30}$ ) and an added value effect of combining LLLT with exercise therapy. The authors suggest these positive findings are in spite of a negative publication bias across relevant LLLT literature. Only 2 studies present results for medium-term outcomes of LLT which show positive effects observed up to 24 weeks. ${ }^{29}$ Although no adverse responses were reported for LLLT in either systematic review, this treatment may not be universally available. 
Table 2 Randomized controlled trials published subsequent to the latest systematic reviews on exercise and orthotics

\begin{tabular}{|c|c|c|c|c|}
\hline Author & $\begin{array}{l}\text { Number } \\
\text { randomized }\end{array}$ & Interventions & Outcome measures & Results \\
\hline Stasinopoulos et $a^{36}$ & 70 & $\begin{array}{l}\text { Home exercise program } \\
\text { or } \\
\text { Supervised exercise program }\end{array}$ & $\begin{array}{l}\text { Pain-VAS } \\
\text { Function—VAS } \\
\text { Pain-free grip strength }\end{array}$ & $\begin{array}{l}\text { Significant decline in pain, rise in } \\
\text { function in both groups on baseline } \\
\text { Significant differences in favor of } \\
\text { supervised exercise for reduction } \\
\text { of pain and rise in } 12 / 52 \text { and at } 3 / 12 \\
\text { follow up }\end{array}$ \\
\hline Garg et $\mathrm{a}^{37}$ & 44 & $\begin{array}{l}\text { Wrist splint } \\
\text { or } \\
\text { Counterforce forearm strap }\end{array}$ & $\begin{array}{l}\text { MEP } \\
\text { ASES Elbow Assessment Form }\end{array}$ & $\begin{array}{l}\text { No significant difference between } \\
\text { the groups with the ASES or MEP } \\
\text { scores } \\
\text { However, within the ASES-derived } \\
\text { score, pain relief was significantly } \\
\text { better with the extension splint } \\
\text { group }\end{array}$ \\
\hline
\end{tabular}

Abbreviations: ASES, American Shoulder and Elbow Society; MEP, Mayo Elbow Performance; VAS, visual analog scale.

\section{Regimens of combined physical treatments}

Two high-quality RCTs ${ }^{7,17}(\mathrm{n}=185, \mathrm{n}=194)$ (assessed using a modified PEDro Scale outlined by Bisset et $\mathrm{al}^{31}$ ) have investigated the effectiveness of packages of physiotherapy treatments (common elements include manual therapy, exercise, home exercise, and advice leaflets), with wait and see and steroid injection treatments. The pattern of response to treatments was similar in each study. Physiotherapy showed a significantly superior response compared with wait and see at 6 weeks (number needed to treat, $\mathrm{NNT}=3$ ) but there was no significant difference at 1-year follow up $(\mathrm{NNT}=30)(\mathrm{NNT}$ is defined as the number of patients who need to be treated in order to prevent one additional bad outcome; it is the inverse of the absolute risk reduction. ${ }^{18}$ ) Corticosteroid injections show usual short-term benefits but at 1 year an NNT $=4$ in favor of physiotherapy is seen. An area under the curve analysis reported a significant advantage of physiotherapy over injections for all primary outcomes but only for painfree grip compared with wait and see. ${ }^{17}$ Participants receiving physiotherapy needed less additional treatment than patients in other groups. Authors generally conclude that for most patients a wait and see approach is advisable, although physiotherapy packages can give short- to medium-term benefits without risks associated with steroid injections. ${ }^{7,17}$

\section{Which interventions are not proven?}

Insufficient or inadequate evidence to support clinical recommendations is reported in Cochrane systematic reviews for the following treatments: oral NSAID, paracetamol, and codeine, ${ }^{26}$ orthotics, ${ }^{31,32}$ and acupuncture. ${ }^{33}$ Also for the following physiotherapy treatments delivered individually: exercise $^{31}$ manipulation or manual therapy, ${ }^{31}$ and ultrasound. ${ }^{31}$
Table 2 shows relevant randomized controlled trials published after the latest systematic review.

Patients who fail to respond to conservative measures may be considered for surgery. A Cochrane review investigating the effect of surgery on lateral elbow pain ${ }^{34}$ did not identify any published controlled trials. However a more general review ${ }^{35}$ suggests this may be due to the indications for surgery being not well codified and many different operative techniques being available. A clear consensus on whether any given surgical procedure is superior is yet to be determined.

\section{Which interventions are not likely to be beneficial?}

Eleven of 13 pooled analyses undertaken as part of a Cochrane review $^{38}$ found no significant benefit of extracorporeal shockwave therapy (ESWT) over placebo. A later review using a different method to assess treatment protocols ${ }^{39}$ reported a subgroup analysis indicating that positive results are associated with adequate treatment doses. However since evidence of efficacy is inconsistent, the United Kingdom National Institute for Health and Clinical Excellence (NICE) guidelines (N1975) (2009) state that the procedure should be used only for refractory tennis elbow with special arrangements for clinical governance, consent, audit, or research. In terms of adverse effects, ESWT may be associated with transient pain, nausea, and local reddening. ${ }^{38}$

\section{Conclusion}

There is no true consensus on the most efficacious management of LE especially for long-term outcomes. Furthermore, most studies do not differentiate between clinical and statistical significant effects. Although corticosteroid injections do show large effect sizes in pain reduction, this 
is seen only in the short term and the treatment is associated with risks of adverse events and long-term reoccurrence. If available, LLLT may be a safe alternative choice for beneficial but smaller short-term effects, especially if considered as an adjunct to exercise therapy. Combined physiotherapy treatment packages have been shown to give relief in the medium term but effects are only slightly better than advice and a wait and see approach in the long term. There is very limited evidence to support injection of blood plasma or botulium toxin in refractory LE. Advice with a wait and see approach are recommended as the first-line treatment in primary care for most cases.

\section{The practice}

\section{Avoiding the pitfalls}

The aim of treatment is to reduce pain and improve function, with minimal adverse effects.

\section{Alternative diagnosis}

Referred pain from the neck or shoulder and local elbow causes including olecranon bursitis, osteoarthritis, and posterior interosseous nerve compression.

\section{Management}

Most lateral epicondylagia can be managed in primary care setting. Indications for onward referral are given below.

\section{Assessment}

- Diagnosis is made following history and examination; further investigations are not required.

- A detailed social and occupational history is important in determining the cause of the LE and the impact. Occupations that involve repetitive and forceful arm actions of turning or lifting, such as plumbers, painters and decorators. bricklayers, and gardeners, are particularly at risk as are full-time keyboard users.

- Palpate around the affected elbow joint to identify the area of maximum pain usually over the common extensor tendon/lateral epicondyle.

- Look for pain in the elbow when pressure is applied while extending the wrist and holding against resistance, or when pressure is applied while twisting the forearm. There may be some forearm pain coupled with limited range of elbow movement; paraesthesia or pain above the elbow is unlikely.

\section{Treatment}

In the acute stage:

- Give advice on the self-limiting nature of the pathology if adequate steps to avoid aggravation of symptoms are taken.

- Give advice on modification of aggravating activities:

- Avoid lifting, especially heavy weights,
- Lift objects close to the body, with elbow bent and palm facing upwards

- Avoid repetitive gripping and twisting activities,

- Take regular breaks from all activities involving the upper limb,

- Suggest the patient seek "light duties" which avoid tasks aggravating the condition at work if possible.

- Offer analgesia or NSAID medication if clinically appropriate. Although evidence for analgesia and NSAID are inconclusive, patients may opt to try pain relieving medication.

If symptoms persist beyond 12 weeks but are less than 26 weeks, discuss other options including:

- Referral to physiotherapy for supervised and home exercise programs and manual therapy.

- Laser therapy (of the correct dose) could be considered.

- For short-term relief of severe pain consider corticosteroid injections. However consideration of long-term relapses and the likelihood of adverse effects should be discussed with the patient.

For recalcitrant tennis elbow (lasting more than 12 months) consider:

- Injections or PRP or prolotherapy.

- Surgery.

\section{Indications for specialist referral}

- A history of significant trauma.

- Failure to respond to conservative treatment after 12 months.

- Failure of symptoms to improve beyond 12 months.

- Unexplained paraesthesia in the arm.

\section{Common ways to assess progress}

\section{in LE rehabilitation}

The Patient-Rated Tennis Elbow Evaluation (PRTEE) is a quick and inexpensive questionnaire to assess subjective outcomes of pain and function. 
Pain free grip (PFG) measured using a dynamometer is a simple objective marker.

\section{Further reading}

\section{UK NHS Clinical Knowledge Summaries} http://www.cks.nhs.uk/tennis_elbow

\section{References}

1. Stasinopoulos D, Johnson MI. 'Lateral elbow tendinopathy' is the most appropriate diagnostic term for the condition commonly referred-to as lateral epicondylitis. Med Hypotheses. 2006;67(6):1400-1402.

2. Coombes BK, Bisset L, Vicenzino B. A new integrative model of lateral epicondylalgia. Br J Sports Med. 2009;43(4):252-258.

3. Hamilton PG. The prevalence of humeral epicondylitis: a survey in general practice. J R Coll Gen Pract. 1986;36(291):464-465.

4. Smidt N, Lewis M, DA VDW, Hay EM, Bouter LM, Croft P. Lateral epicondylitis in general practice: course and prognostic indicators of outcome. J Rheumatol. 2006;33(10):2053-2059.

5. Allander E. Prevalence, incidence, and remission rates of some common rheumatic diseases or syndromes. Scand J Rheumatol. 1974;3(3):145-153.

6. Shiri R, Viikari-Juntura E, Varonen H, Heliovaara M. Prevalence and determinants of lateral and medial epicondylitis: a population study. Am J Epidemiol. 2006;164(11):1065-1074.

7. Smidt N, van der Windt DA, Assendelft WJ, Deville WL, Korthals-de Bos IB, Bouter LM. Corticosteroid injections, physiotherapy, or a waitand-see policy for lateral epicondylitis: a randomised controlled trial. Lancet. 2002;359(9307):657-662.

8. Ranney D, Wells R, Moore A. Upper limb musculoskeletal disorders in highly repetitive industries: precise anatomical physical findings. Ergonomics. 1995;38(7):1408-1423.

9. van Rijn RM, Huisstede BM, Koes BW, Burdorf A. Associations between work-related factors and specific disorders at the elbow: a systematic literature review. Rheumatology (Oxford). 2009;48(5):528-536.

10. Village J, Frazer M, Cohen M, Leyland A, Park I, Yassi A. Electromyography as a measure of peak and cumulative workload in intermediate care and its relationship to musculoskeletal injury: an exploratory ergonomic study. Appl Ergon. 2005;36(5):609-618.

11. Smidt N, Assendelft W, Van der Windt DA, Hay EM, Buchbinder R, Bouter L. Corticosteroid injections for tennis elbow (protocol). Cochrane Database Syst Rev. 2008(4).

12. Smidt N, Assendelft WJ, van der Windt DA, Hay EM, Buchbinder R, Bouter LM. Corticosteroid injections for lateral epicondylitis: a systematic review. Pain. 2002;96(1-2):23-40.

13. Gaujoux-Viala C, Dougados M, Gossec L. Efficacy and safety of steroid injections for shoulder and elbow tendonitis: a meta-analysis of randomised controlled trials. Ann Rheum Dis. 2009;68(12):1843-1849.

14. Coombes BK, Bisset L, Vicenzino B. Efficacy and safety of corticosteroid injections and other injections for management of tendinopathy: a systematic review of randomised controlled trials. Lancet. 2010;376(9754):1751-1767.

15. Barr S, Cerisola FL, Blanchard V. Effectiveness of corticosteroid injections compared with physiotherapeutic interventions for lateral epicondylitis: a systematic review. Physiotherapy. 2009;95(4):251-265.

16. Peerbooms JC, Sluimer J, Bruijn DJ, Gosens T. Positive effect of an autologous platelet concentrate in lateral epicondylitis in a double-blind randomized controlled trial: platelet-rich plasma versus corticosteroid injection with a 1-year follow-up. Am J Sports Med. 2010;38(2):255-262.

17. Bisset L, Beller E, Jull G, Brooks P, Darnell R, Vicenzino B. Mobilisation with movement and exercise, corticosteroid injection, or wait and see for tennis elbow: randomised trial. BMJ. 2006;333(7575):939.
18. Sackett DL, Straus SE, Richardson WS, Rosenberg W, Haynes RB. More Details on Number Needed to Treat (NNT). Centre for evidence-based medicine-Glossary of EBM Terms. http://ktclearinghouse.ca/cebm/ glossary/nnt. Accessed April 42011.

19. Rabago D, Best TM, Zgierska AE, Zeisig E, Ryan M, Crane D. A systematic review of four injection therapies for lateral epicondylosis: prolotherapy, polidocanol, whole blood and platelet-rich plasma. $\mathrm{Br} J$ Sports Med. 2009;43(7):471-481.

20. Kalichman L, Bannuru RR, Severin M, Harvey W. Injection of Botulinum Toxin for Treatment of Chronic Lateral Epicondylitis: Systematic Review and Meta-Analysis. Semin Arthritis Rheum. 2010 Sep 3. [Epub ahead of print]

21. Petrella RJ, Cogliano A, Decaria J, Mohamed N, Lee R. Management of Tennis Elbow with sodium hyaluronate periarticular injections. Sports Med Arthrosc Rehabil Ther Technol. 2010;2:4.

22. Akermark C, Crone H, Elsasser U, Forsskahl B. Glycosaminoglycan polysulfate injections in lateral humeral epicondylalgia: a placebocontrolled double-blind trial. Int J Sports Med. 1995;16(3): 196-200.

23. Zeisig E, Fahlstrom M, Ohberg L, Alfredson H. Pain relief after intratendinous injections in patients with tennis elbow: results of a randomised study. Br J Sports Med. 2008;42(4):267-271.

24. Kazemi M, Azma K, Tavana B, Rezaiee Moghaddam F, Panahi A. Autologous blood versus corticosteroid local injection in the short-term treatment of lateral elbow tendinopathy: a randomized clinical trial of efficacy. Am J Phys Med Rehabil. 2010;89(8):660-667.

25. Ozturan KE, Yucel I, Cakici H, Guven M, Sungur I. Autologous blood and corticosteroid injection and extracoporeal shock wave therapy in the treatment of lateral epicondylitis. Orthopedics.;33(2):84-91.

26. Green S, Buchbinder R, Barnsley L, et al. Non-steroidal anti-inflammatory drugs (NSAIDs) for treating lateral elbow pain in adults. Cochrane Database Syst Rev. 2002(2):CD003686.

27. Tumilty S, Munn J, McDonough S, Hurley DA, Basford JR, Baxter GD. Low level laser treatment of tendinopathy: a systematic review with meta-analysis. Photomed Laser Surg. 2010;28(1):3-16.

28. (WALT) WAoLT. Standards for the design and conduct of systematic reviews with low-level laser therapy for musculoskeletal pain and disorders. Photomed Laser Surg. 2006;24(6):759-760.

29. Bjordal JM, Lopes-Martins RA, Joensen J, et al. A systematic review with procedural assessments and meta-analysis of low level laser therapy in lateral elbow tendinopathy (tennis elbow). BMC Musculoskelet Disord. 2008;9:75.

30. World Association of Laser Therapy (WALT). Recommended treatment doses for Low Level Laser Therapy -Laser class 3B, $904 \mathrm{~nm}$ GaAs Lasers. Dosage recommendations. http://www.walt.nu/images/stories/ files/Dose_table_904 nm_for_Low_Level_Laser_Therapy_WALT2010.pdf. Accessed April 12, 2011.

31. Bisset L, Paungmali A, Vicenzino B, Beller E. A systematic review and meta-analysis of clinical trials on physical interventions for lateral epicondylalgia. Br J Sports Med. 2005;39(7):411-422; discussion 411-422.

32. Struijs PA, Smidt N, Arola H, van Dijk CN, Buchbinder R, Assendelft WJ. Orthotic devices for tennis elbow. Cochrane Database Syst Rev. 2001(2):CD001821.

33. Green S, Buchbinder R, Barnsley L, et al. Acupuncture for lateral elbow pain. Cochrane Database Syst Rev. 2002(1):CD003527.

34. Buchbinder R, Green S, Bell S, Barnsley L, Smidt N, Assendelft WJ. Surgery for lateral elbow pain. Cochrane Database Syst Rev. 2002(1):CD003525.

35. Karkhanis S, Frost A, Maffulli N. Operative management of tennis elbow: a quantitative review. Br Med Bull. 2008;88(1):171-188.

36. Stasinopoulos D, Stasinopoulos I, Pantelis M, Stasinopoulou K. Comparison of effects of a home exercise programme and a supervised exercise programme for the management of lateral elbow tendinopathy. Br J Sports Med. 2010;44(8):579-583. 
37. Garg R, Adamson GJ, Dawson PA, Shankwiler JA, Pink MM. A prospective randomized study comparing a forearm strap brace versus a wrist splint for the treatment of lateral epicondylitis. J Shoulder Elbow Surg. 2010;19(4):508-512.

38. Buchbinder R, Green SE, Youd JM, Assendelft WJ, Barnsley L, Smidt N. Shock wave therapy for lateral elbow pain. Cochrane Database Syst Rev. 2005(4):CD003524.
39. Rompe JD, Maffulli N. Repetitive shock wave therapy for lateral elbow tendinopathy (tennis elbow): a systematic and qualitative analysis. Br Med Bull. 2007;83:355-378.

Open Access Journal of Sports Medicine

\section{Publish your work in this journal}

Open Access Journal of Sports Medicine is an international, peer-reviewed, open access journal publishing original research, reports, reviews and commentaries on all areas of sports medicine. The manuscript management system is completely online and includes a very quick and fair peer-review system.
Visit http://www.dovepress.com/testimonials.php to read real quotes from published authors. 